\title{
Differential behavioral, physiological, and hormonal sensitivity to LPS challenge in rats
}

\author{
Silvia Bison' \\ Lucia Carboni' \\ Roberto Arban' \\ Simon Bate ${ }^{2}$ \\ Philip A Gerrard' \\ Maria Razzoli' \\ 'Department of Biology, \\ Neurosciences Centre of Excellence \\ for Drug Discovery, GlaxoSmithKline, \\ Medicines Research Centre, \\ Verona, Italy; ${ }^{2}$ Statistical Sciences, \\ GlaxoSmithKline, New Frontiers \\ Science Park, Harlow, Essex \\ CMI95AW, UK
}

\begin{abstract}
In animals, systemic administration of lipopolysaccharide (LPS) induces a characteristic set of responses that has been termed sickness behavior. In the present study, the effects of a wide dose range of LPS injections on behavior and physiology were examined in rats. Male rats were injected IP with either saline or LPS $(1,5,15,50,125$, or $250 \mu \mathrm{g} / \mathrm{kg})$. Body temperature, body weight, and home-cage activity were monitored over $24 \mathrm{~h}$ after injection. Behaviorally the social interaction and the saccharin preference tests were assessed at 2 and $24 \mathrm{~h}$ post-injection, respectively. Further animals were treated with LPS to assess hypothalamic-pituitary adrenal (HPA) axis and immune system responses $2 \mathrm{~h}$ post-injection. LPS significantly reduced body weight ( $1 \mu \mathrm{g} / \mathrm{kg}$ and above), increased ACTH (15 $\mu \mathrm{g} / \mathrm{kg}$ and above) and serum corticosterone levels ( $5 \mu \mathrm{g} / \mathrm{kg}$ and above). In addition LPS raised serum interleukins ( $5 \mu \mathrm{g} / \mathrm{kg}$ and above) and tumor necrosis factor-alpha ( $1 \mu \mathrm{g} / \mathrm{kg}$ and above). Social behavior and preference for saccharin were significantly decreased at all doses of LPS tested $(1-250 \mu \mathrm{g} / \mathrm{kg}$ ) while a robust reduction in home-cage activity was observed starting at $15 \mu \mathrm{g} / \mathrm{kg}$. The present finding suggests that LPS caused profound behavioral alterations and stimulation of the immune system even at very low doses.
\end{abstract}

Keywords: sickness behavior, lipopolysaccharide, cytokines, ACTH, corticosterone, social interaction

\section{Introduction}

Clinical depression is a complex phenomenon reflecting many subtypes and different aetiologies. Beyond the recognized role of monoaminergic systems in the pathophysiology of depression, recent studies have provided a strong link between depression and inflammatory phenomena. ${ }^{1-5}$ Indeed, it has been hypothesized that depressed patients may be suffering from a dysregulation of the immune system with increased production of pro-inflammatory cytokines, such as interleukin-1ß (IL-1ß), IL-6 and tumor necrosis factor-alpha (TNF- $\alpha) \cdot{ }^{6-9}$ Moreover, administration of cytokines is well known to induce unfavorable symptoms which have many features in common with major depression. ${ }^{10}$ Patients receiving interferon-alpha administration for the treatment of hepatitis $\mathrm{C}$ frequently develop major depression symptoms, which can be prevented or treated with antidepressant drugs. ${ }^{11,12}$ Similarly, systemic administration to healthy subjects of the cytokine inducer lipopolysaccharide (LPS), a cell wall component of Gram-negative bacteria, causes a marked increase in the circulating cytokines (eg, IL-1ß, IL-6, and TNF- $\alpha$ ), a concomitant elevation in serum cortisol levels and a significant elevation in negative emotions, including sadness, anxiety, and depressed mood. ${ }^{13-18}$ Accordingly, systemic LPS injection to animals causes effects comparable to those found in humans. In particular, the acute administration of LPS to rats induces depressive-like symptoms known as "sickness behavior" which includes loss of interest or pleasure (anhedonia), impaired cognitive function, retardation of motor activity, reduced interest in exploration, and decrease in social activities. ${ }^{19-22}$ However, results 
obtained so far in animal studies are difficult to interpret, since the "depressive-like" components induced by LPS challenge may overlap with more general psychomotor disturbances. Investigations to date have been limited to doses and time points at which LPS produced a maximal effect on neuroendocrine, inflammatory, and behavioral parameters. The present study was designed to investigate the effects of LPS, from low to high doses, on the behavioral, physiological and neuroendocrine responses in the rat. In particular, it was considered important to explore to what extent a wide dose range of LPS would modulate psychological stress in an attempt to dissect specific behavioral components from less specific psychomotor symptoms.

\section{Materials and methods}

\section{Animals}

Adult male Sprague Dawley rats (Charles River, Calco, Italy), weighing between 280 and $360 \mathrm{~g}$ at the start of testing, were used in these experiments. Singly housed animals were acclimatised for one week in a room controlled for temperature $\left(22 \pm 1{ }^{\circ} \mathrm{C}\right)$, humidity $(60 \%)$, and lighting (12 h light-dark cycle; lights on $0600 \mathrm{~h}$ ). Food and water were provided ad libitum throughout the experiment. All experiments were performed in accordance with European Community ethical regulations on the care of animals for scientific research (CEE Council 86/609 Italian D.L. 27/01/92 no. 116) and were fully compliant with GlaxoSmithKline ethical standards.

\section{Experimental procedure}

The study herein reported consisted of six different cohorts of animals, all of which received the same LPS treatment
(Figure 1). All cohorts of animals received an intraperitoneal (IP) injection of LPS ranging from 1 to $250 \mu \mathrm{g} / \mathrm{kg}$.

The first two cohorts of animals were used to measure home cage activity and social interaction. Body weight and body temperature were also measured. Eight to 10 rats/ group/cohort were used. Evaluation of hormone and cytokine peripheral levels were carried out in other three animal cohorts to avoid confounding effects on these biochemical parameters due to manipulation of the animals ( $n=5$ to 8 rats/group/ cohort). An additional set of animals ( $\mathrm{n}=9$ to 10 rats/group) was used to carry out the saccharin preference test.

\section{Challenge}

LPS derived from Escherichia coli O111:B4 serotype was purchased from Sigma-Aldrich (Milan, Italy) and stored at $4{ }^{\circ} \mathrm{C}$ until use. The LPS solutions were freshly prepared in sterile pyrogen-free saline and administered IP at the doses of $1,5,15,50,125$, or $250 \mu \mathrm{g} / \mathrm{kg}$ ( $2 \mathrm{~mL} / \mathrm{kg}$ body weight $)$. Control animals received IP saline injections ( $2 \mathrm{~mL} / \mathrm{kg}$ body weight). Treatments were conducted during the light phase of a $12 \mathrm{~h}$ light-dark cycle, between 0800-1000 h, except for animals undergoing the saccharin preference test which received injections 3-4 h prior light-off, between 1400-1500 h.

\section{Behavioral tests}

\section{Social interaction}

The test arena consisted of a rectangular black perspex box $(54 \mathrm{~cm} \times 36 \mathrm{~cm})$ with walls $33 \mathrm{~cm}$ high, and a white floor divided in $9 \mathrm{~cm}$ squares $(4 \times 6)$ for the line crossing read out. Three walls were black and one transparent in order to assist video recording. The day before the test, rats

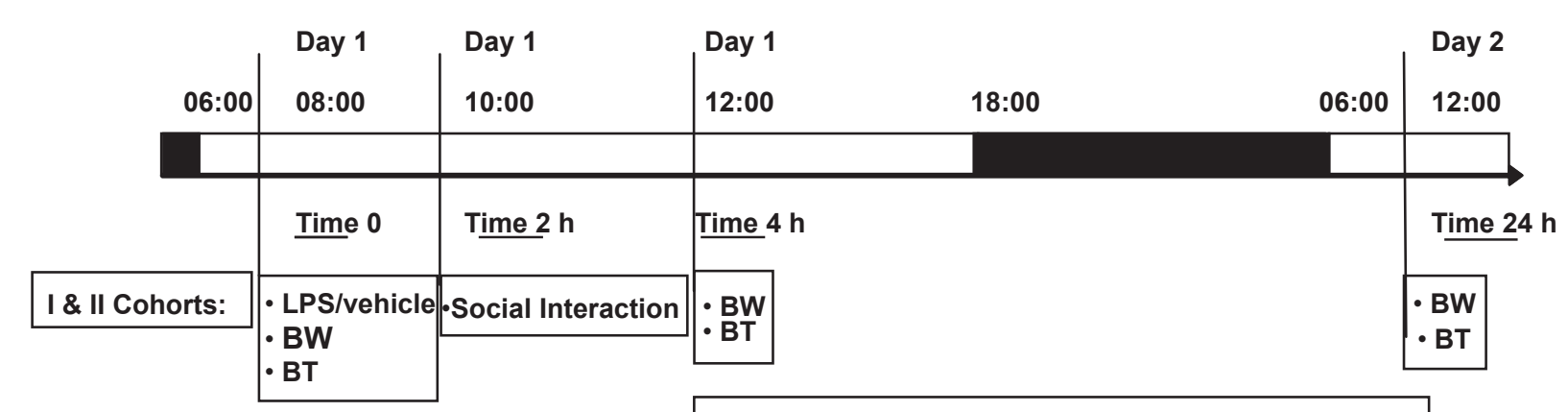

- Home- cage activity LABORAS ${ }^{\circledR}$

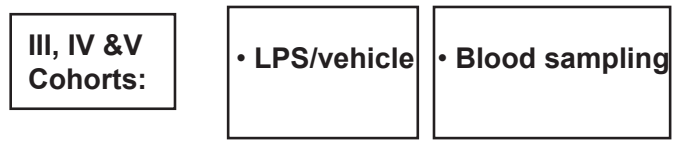

Figure I Description of the experimental procedure used in the current study. Abbreviations: BW, body weight; BT, body temperature. 
(cohorts I and II; Figure 1) were placed individually in the arena for a $5 \mathrm{~min}$ familiarization period. Two hours after LPS or saline injection, a social interaction test was performed by placing treated pairs of rats ( $\mathrm{n}=8$ to $10 \mathrm{rats} /$ group/cohort), matched for body weight and unfamiliar to each other, into the test arena and their behavior was video-recorded for $15 \mathrm{~min}$. All experiments were carried out in dim light (2 Lux) between 1000-1200 h. At the end of the social interaction test, each animal was returned to its home-cage. The Observer $^{\circledR}$ (Noldus, Wageningen, The Netherlands) software for collection and analysis of observational data was used for scoring duration of social interaction (grooming, following and sniffing of the partner body) and frequency of line crossing (number of lines crossed on the base of arena) by an experienced observer blind to experimental groups.

\section{Home cage activity (LABORAS ${ }^{\circledR}$ )}

The spontaneous home-cage activity was monitored with the automated individual cage system LABORAS ${ }^{\circledR}$ (Laboratory Animal Behavior Observation, Registration and Analysis System, Metris, Hoofddorp, Netherlands). One hour after the social interaction test ( $3 \mathrm{~h}$ post-LPS injection) each rat (cohorts I and II; Figure 1) was transferred from its home cage and placed individually with its own bedding in a Makrolon type III cage $\left(840 \mathrm{~cm}^{2}\right)$ and behavior was recorded during a $24 \mathrm{~h}$ period. Drinking water and food pellets were provided ad libitum for the entire period of the test session. The cumulative time spent (seconds) on each of the following behaviors was assessed automatically: locomotion (activities such as walking and running), immobility (absence of movements while the animal is in a lying position), rearing (the animal standing upright on its hind legs mostly against the wall), grooming (shaking, scratching, or licking). The total distance was also assessed and expressed as total meters traveled by the animal over the time point examined. ${ }^{23}$

\section{Saccharin preference test}

This experiment was designed to assess the effect of LPS on the preference for a palatable solution using a two-bottle paradigm. Rats were allowed for $24 \mathrm{~h}$ to freely choose between a bottle of water and a bottle containing a saccharin solution $(0.1 \% \mathrm{w} / \mathrm{v}$; Sigma-Aldrich) in their home cage with water and food ad libitum. Bottle positions were switched daily with a variable sequence in order to avoid any place preference. For each animal, the total fluid consumption (grams) was measured by weighing bottles before and after each test session ( $24 \mathrm{~h}$ period time) and defined as the sum of water and saccharin intake, whereas the saccharin preference score was expressed as the percentage of saccharin intake $(\%=$ saccharin intake $\times 100$ / total fluid intake). As baseline value for each rat, the total fluid consumption and saccharin preference score were measured over the last $24 \mathrm{~h}$ of adaptation. On the day of the test, two pre-weighed bottles, one containing drinking water and another containing saccharin solution, were presented to each rat immediately after the IP injection of either saline or LPS $(1-250 \mu \mathrm{g} / \mathrm{kg})$. The bottles were weighed again $24 \mathrm{~h}$ after LPS challenge (1400-1500 h) and the weight difference was considered as the intake from each bottle. The timing of LPS treatment was selected based on earlier studies conducted by Shen and colleagues. ${ }^{21}$

\section{Physiological parameters \\ Body temperature}

Four days prior to the test session, rats (cohorts I and II; Figure 1) were implanted subcutaneously with microchip transponders (IPTT-200; BioMedic Data System, Inc., Seaford, DE, USA), for body temperature recording. Measurements of body temperature were obtained from freely moving animals using a DAS-5007 Pocket Scanner System (BioMedic Data System, Inc.).

To obtain baseline measurements each rat was monitored the day before the test session 0800-1000 h. On the test day, temperature recording occurred immediately before $(\mathrm{T}=0)$ as well as at two $(\mathrm{T}=2)$, four $(\mathrm{T}=4)$, and $24 \mathrm{~h}(\mathrm{~T}=24)$ after injection of either LPS or saline.

\section{Body weight}

On the test day, the body weight (BW) of each animal (cohorts I and II; Figure 1) was measured immediately before $(\mathrm{T}=0)$ as well as at four $(\mathrm{T}=4)$ and $24 \mathrm{~h}(\mathrm{~T}=24)$ after injection of either LPS or saline.

\section{Hormone and cytokine levels Blood sampling}

Rat cohorts III to V (Figure 1) were sacrificed by guillotine decapitation $2 \mathrm{~h}$ after LPS administration for blood sample collection. For plasma preparation, trunk blood was collected into $1 \mathrm{ml} \mathrm{K} 3$ EDTA tubes (BD Biosciences, Erembodegen, Belgium), centrifuged $10 \mathrm{~min}$ at $3000 \mathrm{~g}$ at $4{ }^{\circ} \mathrm{C}$ and stored at $-80^{\circ} \mathrm{C}$ until the day of the experiment. Serum was prepared by collecting trunk blood in Microtainer tubes (BD Biosciences), letting the blood clot for $30 \mathrm{~min}$ at room temperature and centrifuging at $3000 \mathrm{~g}$ for $15 \mathrm{~min}$ at $4{ }^{\circ} \mathrm{C}$. A protease inhibitor cocktail (Protease Inhibitor Mix, Amersham Biosciences, Uppsala, Sweden) was added to supernatants and aliquots were stored at $-80^{\circ} \mathrm{C}$ until measurement. 


\section{Plasma ACTH and serum corticosterone levels}

Adrenocorticotropic hormone (ACTH) levels were measured in plasma with an IRMA kit (Nichols Institute Diagnostics, San Clemente, CA, USA). Corticosterone levels were measured in serum, using a RIA kit(RIA Immuchem ${ }^{\text {TM }}$ Double antibody ${ }^{125}$ I RIA kit, MP Biomedicals, Irvine, CA, USA). Experiments were carried out following the manufacturers' protocol.

\section{Cytokine serum levels}

IL-1 1 , IL-6, IL-10, and TNF- $\alpha$ levels were measured in serum with a Luminex instrument, using a multiplex suspension array technology (Bio-Rad, Hercules, CA, USA). In this assay, each specific primary antibody recognizing a cytokine is conjugated to a distinct type of fluorescent bead. All antibody-bearing beads are added simultaneously to the sample, allowing the formation of immunocomplexes. The different immunocomplexes are detected by binding to specific biotinylated antibodies and then to streptavidin-phycoeritrin. The quantification is carried out by the Luminex instrument by identifying the kind of bead, which is specific for each analyte and by evaluating the fluorescence intensity, which is related to the concentration of the analyte in solution. A comparison with a standard curve is carried out to obtain concentration values. The assays were carried out using a Bio-plex instrument (Bio-Rad) and all kits and reagents were obtained from Bio-Rad. Briefly, after rinsing wells with assay buffer, antibody conjugated beads were loaded onto the kit plates. Rat serum samples were diluted 1:4 with rat serum sample diluent and $50 \mu \mathrm{L}$ were loaded on the kit plates in duplicate. A standard cytokine lyophilysed mix was dissolved in rat serum standard diluent and plates were loaded with $50 \mu \mathrm{L} /$ well. After $30 \mathrm{~min}$ incubation at room temperature under agitation in the dark, samples were washed three times by filtration. Incubation with biotinylated secondary antibody and phycoeritrin-conjugated streptavidin were carried out following the same scheme. Fluorescence values were collected and analysed with the Bio-Plex Manager program (detection limits: IL-1ß 7.8 pg/mL; IL-6 31.25 pg/mL; IL-10 $7.8 \mathrm{pg} / \mathrm{mL}$, and TNF- $\alpha 7.8 \mathrm{pg} / \mathrm{mL}$ ).

\section{Statistical analysis}

Statistical analyses were conducted using either Statistica V6.1 (Statsoft, Inc. Tulsa, OK, USA) or SAS ${ }^{\circledR}$ (SAS Institute Inc., Cary, NC, USA).

The data from the separate cohorts of animals including the social interaction, home cage activity and the biochemical read-out, were combined into one dataset and analyzed by one-way ANOVA with cohort as a blocking factor, followed by planned comparisons on the predicted means.
Because the body weight, body temperature and the saccharin preference test were measured repeatedly over time, a repeated measures (treatment $\times$ time) approach was used, with the baseline measurements $(\mathrm{T}=0)$ also included as a covariate in the analysis (ANCOVA approach), followed by planned comparison on the predicted means.

Results from all studies were expressed as the predicted mean \pm standard error of the mean (SEM). We use predicted means rather than the more usual observed means as the predicted means take into account differences between the cohorts and, where covariates were used, baseline values. In all studies, levels of statistical significance were set at $p<0.05$.

\section{Results}

\section{Social interaction test}

An overall significant decrease in the time spent in social interaction occurred following LPS treatment compared to vehicle treated animals, $\mathrm{F}(6,97)=4.355, p<0.001$; Figure 2A. LPS administration provoked significant changes $(p<0.05-p<0.001)$ in the social interaction from 1 to $125 \mu \mathrm{g} / \mathrm{kg}$. Furthermore, LPS caused a significant reduction in the locomotor activity, $\mathrm{F}(6,97)=7.017$, $p<0.001$; Figure 2B, as assessed by reduction in the linecrossing frequency at all doses tested $(p<0.05-p<0.001)$ with the exception of $1 \mu \mathrm{g} / \mathrm{kg}$ LPS.

\section{Home-cage activity}

Home-cage activity parameters were altered by treatment with LPS over a 44 h period time compared to control animals (Table 1). LPS treatment did not affect home-cage activity at any of lower doses tested ( $1 \mu \mathrm{g} / \mathrm{kg}$ to $5 \mu \mathrm{g} / \mathrm{kg}$ ) whereas it induced a significant decrease in locomotor activity, expressed both in terms of duration, $\mathrm{F}(5,49)=3.774, p<0.01$, and distance travelled, $\mathrm{F}(5,49)=4.307, p<0.01$, with effective doses of 15,50 , and $125 \mu \mathrm{g} / \mathrm{kg}(p<0.05-p<0.001$; Table 1). Rearing behavior was significantly decreased by LPS, $\mathrm{F}(5,49)=4.972$, $p<0.001$, particularly this decrease was observed at doses of $15 \mu \mathrm{g} / \mathrm{kg}$ and above $(p<0.01-p<0.001)$. Accordingly, immobility was significantly increased following LPS treatment $\mathrm{F}(5,49)=4.864, p<0.01$, at the dose of $15 \mu \mathrm{g} / \mathrm{kg}$ and above $(p<0.05-p<0.01)$. In addition, a marked decrease in grooming duration was detected in animals treated with the highest LPS doses 50 and $125 \mu \mathrm{g} / \mathrm{kg}, \mathrm{F}(5,49)=3.966, p<0.01$, with either doses being effective ( $p<0.01$ for each).

\section{Saccharin preference test}

In the baseline session when given a free choice between tap water and saccharin solution all rats displayed a 


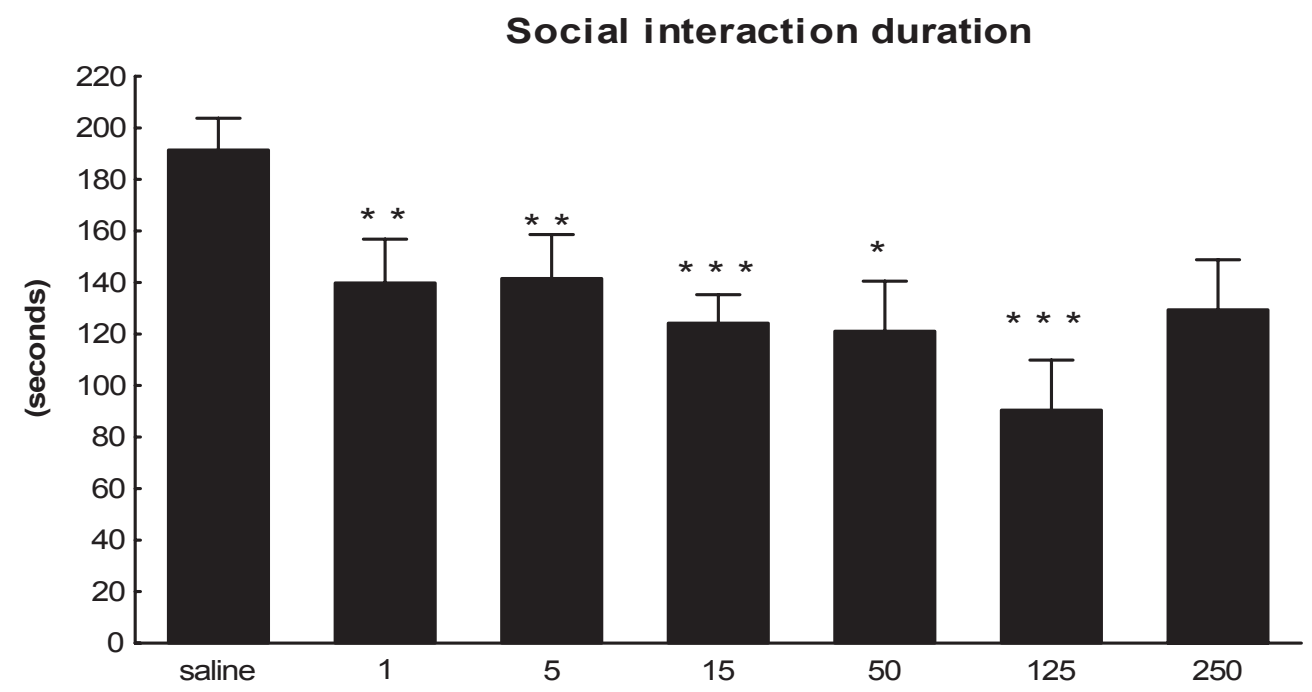

A

$\mu \mathrm{g} / \mathrm{kg}$, IP LPS

Line-crossing frequency

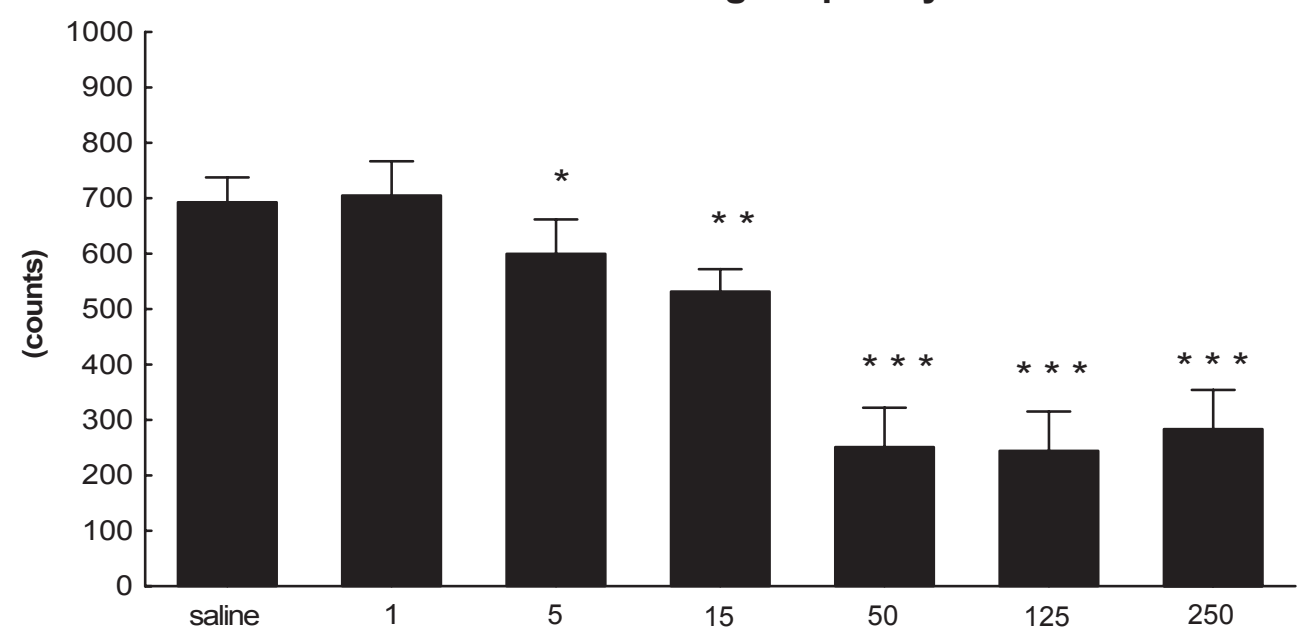

B

$\mu \mathrm{g} / \mathbf{k g}$, IP LPS

Figure 2 Effects of lipopolysaccharide (LPS) in the rat social interaction test: social interaction duration (A) and line-crossing frequency (B) LPS was injected IP 2 h before the test session.

Notes: Predicted means \pm SEM are shown ( $\mathrm{n}=8$ to 10 rats /group/cohort). Asterisks represent significant differences detected by planned comparisons between individual treatment groups and vehicle group. ${ }^{*} p<0.05$; ${ }^{* * p}<0.01$; ***p $<0.001$.

Table I Effect of lipopolysaccharide (LPS) on home-cage parameters over $24 \mathrm{~h}$ after the injection

\begin{tabular}{|c|c|c|c|c|c|}
\hline \multicolumn{6}{|c|}{ Home-cage activity parameters } \\
\hline Group & Locomotion (s) & Immobility (s) & Rearing (s) & Grooming (s) & Total distance $(\mathrm{m})$ \\
\hline saline & $576 \pm 49$ & $53230 \pm 1220$ & $4991 \pm 343$ & $12024 \pm 621$ & $5 \mathrm{I} \pm 4.2$ \\
\hline LPS I $\mu g / k g$ & $536 \pm 80$ & $56 \mid 48 \pm 2011$ & $4228 \pm 565$ & $10503 \pm 1023$ & $44 \pm 6.8$ \\
\hline LPS $5 \mu g / \mathrm{kg}$ & $554 \pm 80$ & $57397 \pm 2011$ & $4439 \pm 565$ & $10241 \pm 1023$ & $44 \pm 6.8$ \\
\hline LPS I5 $\mu g / \mathrm{kg}$ & $351 \pm 80^{*}$ & $61136 \pm 2011^{*}$ & $2994 \pm 565^{* *}$ & $9198 \pm 1023$ & $28 \pm 6.8^{*}$ \\
\hline LPS $50 \mu g / \mathrm{kg}$ & $308 \pm 77^{k \cdots k}$ & $59178 \pm 1939^{* *}$ & $2772 \pm 544^{\text {**ak }}$ & $8813 \pm 987^{* *}$ & $26 \pm 6.6^{\text {*⿻*k }}$ \\
\hline LPS $125 \mu g / \mathrm{kg}$ & $286 \pm 77^{k+k o k}$ & $61257 \pm 1939^{* *}$ & $2691 \pm 544^{\text {*atk }}$ & $7598 \pm 987^{* *}$ & $24 \pm 6.6^{\text {kok }}$ \\
\hline
\end{tabular}

Notes: Predicted means \pm SEM are shown. Asterisks represent significant differences detected by planned comparisons between individual treatment groups and vehicle group; ${ }^{*} p<0.05$; ${ }^{*} p<0.01$; $*^{* *} p<0.00$ I (8-10/group/cohort). Data from $250 \mu \mathrm{gg} / \mathrm{kg}$ LPS group were lost. 


\section{Body weight}

Baseline body weights were fitted as covariate to remove some of pre-treatment animal-to-animal variability which could have contributed to a loss of statistical power in capturing the LPS-related effects on body weight. Consequently, an overall effect of treatment, $\mathrm{F}(6,78)=9.40, p<0.001$, and a considerable interaction between the treatment and time, $\mathrm{F}(6,75)=2.97, p<0.01$, were observed. At both $1 \mu \mathrm{g} / \mathrm{kg}$ and $15 \mu \mathrm{g} / \mathrm{kg}$ LPS significantly ( $p<0.05$ and $p<0.01$, respectively; Table 2), reduced BW $4 \mathrm{~h}$ after the injection, but not $24 \mathrm{~h}$ after the injection. LPS at doses of 50,125 , or $250 \mu \mathrm{g} / \mathrm{kg}$ significantly decreased ( $p<0.001$ for each) BW at both 4 and $24 \mathrm{~h}$ following injection.

\section{Body temperature}

The body temperature of rats at pre-injection time was taken as baseline level and the mean value was $36.89 \pm 0.1^{\circ} \mathrm{C}$. The analysis of covariance revealed that there was no evidence of an overall effect of treatment, $\mathrm{F}(6,83)=0.6, p=0.73$, but an effect of time $\mathrm{F}(2,85)=33.38, p<0.001$, and a considerable difference for the main effect of treatment $\mathrm{X}$ time, $\mathrm{F}(12,125)=3.07, p<0.001$ were detected. Planned comparison analysis showed that the highest dose of $250 \mu \mathrm{g} / \mathrm{kg}$ LPS produced a significant decrease on thermal response at $2 \mathrm{~h}$ post injection when compared to saline treated rats ( $p<0.01$; Figure 4). Doses of 5, 15, 125, and $250 \mu \mathrm{g} / \mathrm{kg}$ LPS showed little changes in the body temperature in the $4 \mathrm{~h}$ following challenge. At the last time point examined of $24 \mathrm{~h}$, only the dose of $125 \mu \mathrm{g} / \mathrm{kg}$ LPS induced a marked hyperthermia reaching statistical significance when compared to saline-treated rats $(p<0.001$; Figure 4$)$.

Table 2 Effect of lipopolysaccharide (LPS) on body weight

\begin{tabular}{|c|c|c|}
\hline \multicolumn{3}{|c|}{ Body weight (g) } \\
\hline Group & $4 \mathrm{~h}$ & $24 \mathrm{~h}$ \\
\hline saline & $294 \pm 1.0$ & $295 \pm 2.6$ \\
\hline LPS I $\mu g / k g$ & $290 \pm 1.6^{*}$ & $293 \pm 3.8$ \\
\hline LPS $5 \mu \mathrm{g} / \mathrm{kg}$ & $291 \pm 1.6$ & $291 \pm 3.8$ \\
\hline LPS $15 \mu g / k g$ & $289 \pm 1.0^{* *}$ & $289 \pm 2.4$ \\
\hline LPS $50 \mu \mathrm{g} / \mathrm{kg}$ & $285 \pm 1.8^{* * * *}$ & $277 \pm 3.4^{*+* k}$ \\
\hline 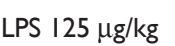 & $284 \pm 1.8^{* * * *}$ & $27 I \pm 3.4^{* k+k}$ \\
\hline LPS $250 \mu \mathrm{g} / \mathrm{kg}$ & $283 \pm 1.4^{* * * *}$ & $280 \pm 3.4^{\text {polke }}$ \\
\hline
\end{tabular}

Notes: Measurements were taken immediately before $(T=0)$ and at 4 and $24 \mathrm{~h}$ after the injection. The results presented in this table are based on predicted means \pm SEM from the analysis (8-10/group/cohort). Asterisks represent significant differences detected by planned comparisons between individual treatment groups and vehicle group. ${ }^{*} p<0.05 ;{ }^{* *} p<0.01 ;{ }^{* * * k} p<0.001$.

\section{Plasma ACTH and serum corticosterone levels}

Injection of LPS caused a significant increase in plasma ACTH levels within $2 \mathrm{~h}$ of injection, $\mathrm{F}(6,56)=4.509, p<0.001$, and this effect was particularly evident at doses from 15 to $250 \mu \mathrm{g} / \mathrm{kg}(p<0.05-p<0.001$, Figure 5B).

Serum corticosterone levels were also altered following LPS challenge, $\mathrm{F}(6,56)=7.792, p<0.001$, being significantly affected at doses from 5 to $250 \mu \mathrm{g} / \mathrm{kg}(p<0.01-p<0.001$; Figure 5A).

\section{Cytokine serum levels}

There was an overall effect of LPS treatment in the IL-1 $\beta$, IL-6 and IL-10 cytokine levels in rat serum $2 \mathrm{~h}$ after LPS injection, $\mathrm{F}(6,55)=14.243, p<0.001 ; \mathrm{F}(6,55)=16.411, p<0.001 ;$ $\mathrm{F}(6,55)=15.943, p<0.001$, respectively. IL-1 $\beta$ and IL-6 levels were significantly increased starting at the $5 \mu \mathrm{g} / \mathrm{kg}$ LPS treatment, $(p<0.001$, Figures $6 \mathrm{~A}$ and $6 \mathrm{~B})$ and IL-10 by the $1 \mu \mathrm{g} / \mathrm{kg}$ LPS treatment $(p<0.01-\mathrm{p}<0.001$, Figure $6 \mathrm{C})$. TNF- $\alpha$ levels also showed a very large increase after LPS challenge, $\mathrm{F}(6,49)=32.975, p<0.001$, which was statistically significant at all doses $(p<0.01-p<0.001$, Figure 6D).

\section{Discussion}

The present investigation demonstrated that systemic administration of LPS elicited profound effects on rat behavior, physiology, circulating stress hormones and cytokines, revealing differential reactivity thresholds for these parameters.

LPS caused a reduction in social interaction at all doses tested. LPS also impaired locomotor activity at all doses tested except $1 \mu \mathrm{g} / \mathrm{kg}$, indicating that the reduction in social interaction at doses above $1 \mu \mathrm{g} / \mathrm{kg}$ could be at least partly ascribed to a general LPS induced decrease of activity. Therefore the decrease in social behavior could be considered independent from sedative-like effects of the endotoxin treatment at $1 \mu \mathrm{g} / \mathrm{kg}$ LPS. Previous studies have shown that peripheral administration of LPS severely depresses social exploration and locomotor activity in the rat. ${ }^{24-26}$ Our results extend these findings and suggest that the decrease in social interaction can be specifically targeted by LPS challenge, and that this decrease may be independent of a general impairment of motor behavior. In addition, a persistent reduction in general activity was also revealed in home-cage conditions. LPS doses of $15 \mu \mathrm{g} / \mathrm{kg}$ and above resulted in a decrease of locomotion, rearing, grooming and mobility. Furthermore, LPS (doses of $15 \mu \mathrm{g} / \mathrm{kg}$ and above) produced a marked reduction in body weight, detectable at the first time 


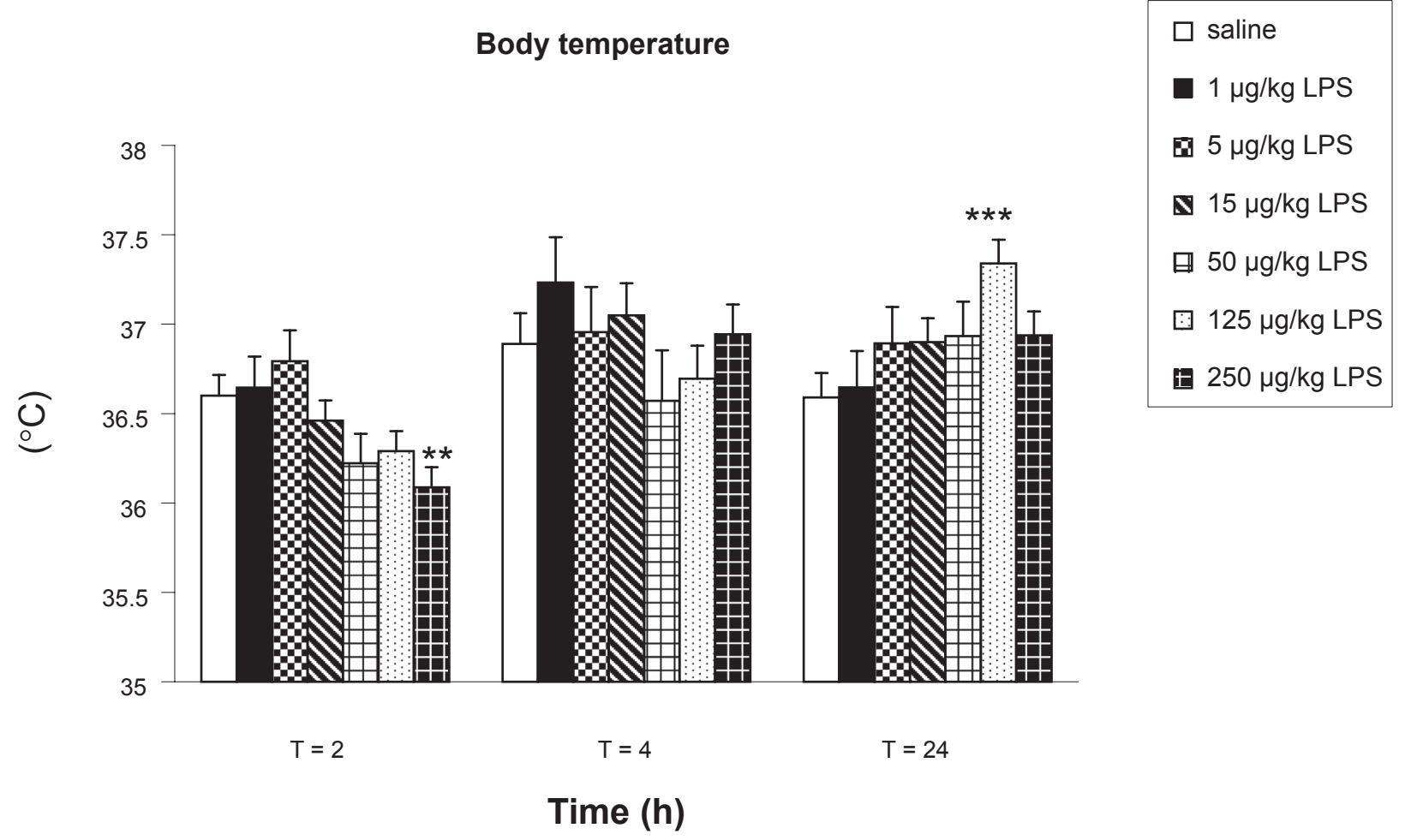

Figure 4 Effects of lipopolysaccharide (LPS) on body temperature at $24 \mathrm{~h}$ post-challenge: the measurements were analyzed using an ANCOVA approach with baseline values $(\mathrm{T}=0)$ included as covariate.

Notes: The results presented in this figure are based on the predicted means \pm SEM ( $n=6$ to I0/group/cohort) from the analysis. Asterisks represent significant differences detected by planned comparisons between individual treatment groups and saline group. ${ }^{* *} p<0.0 \mathrm{I}$; ***p $<0.00$ I.

point of $4 \mathrm{~h}$. However this effect was maintained $24 \mathrm{~h}$ after LPS injection only for the highest doses tested, whereas a complete recover was observed in animals treated with lower endotoxin doses. We did not observe any mortality during our experimental procedure and additional studies conducted in our laboratory confirmed a full recovery of rats treated at $250 \mu \mathrm{g} / \mathrm{kg}$ LPS after $72 \mathrm{~h}$ (data not shown). This finding can be explained considering that rats exhibiting sickness behavior may not have the energy to eat and drink during the recovery period as control animals as well as animals exposed to a lesser challenge of LPS. This effect is in part in agreement with previous reports, showing that relatively high doses of LPS induced weight loss assessed at the same time points as those observed in the current study. ${ }^{27-32}$

LPS did not produce a reliable body temperature response. In particular, a hypothermic effect was observed at the earlier time point of $2 \mathrm{~h}$ for the $250 \mu \mathrm{g} / \mathrm{kg}$ LPS dose, whereas the sole hyperthermic effect was displayed at $24 \mathrm{~h}$ after $125 \mu \mathrm{g} / \mathrm{kg}$ LPS challenge. These findings confirmed the result obtained in previous studies conducted inside our laboratory and directed towards investigating the effect of LPS on BT. We repeatedly observed the same phenomenon: a trend toward either hypothermic or hyperthemic effects that was depending on the dose and timing without reaching a robust or significant effect. The inconsistencies between the results on LPS thermal response in our experiments and literature data could be explained by one or more of the following factors: the serotype and/or doses of LPS, the time point as well as body temperature parameter assessment (ie, rectal versus core versus subcutaneous). ${ }^{33-36}$ For instance, these researchers have discussed the validity of the observed effects of LPS on body temperature, suggesting that it may be extremely variable and time dependent when assessed using a rectal temperature probe. It is also worth noting that a continuous monitoring of the body temperature was not feasible since repeated handling could influence the behavioral/physiological parameters assessed in the present studies.

Nevertheless, the hypothermia observed in the present study at the highest dose of LPS, may be considered as an adaptive thermoregulatory or a survival response to a systemic inflammation.

Findings from our study have shown that LPS produced a reliable decrease in both the total fluid intake and the preference for saccharin in comparison to saline-injected animals over a $24 \mathrm{~h}$ time point. However at doses of $1-15 \mu \mathrm{g} / \mathrm{kg}$, LPS significantly increased water consumption, suggesting 

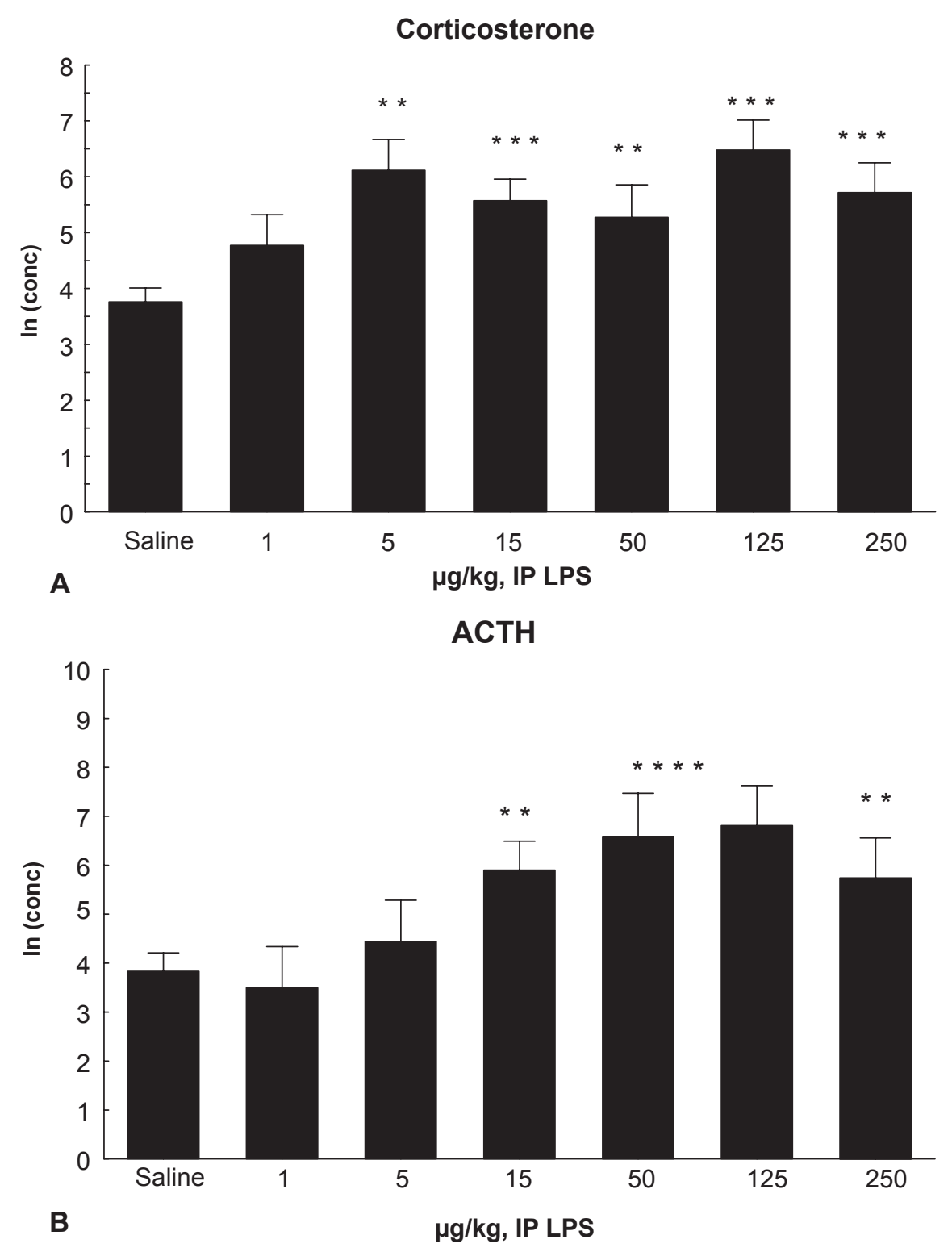

Figure 5 Corticosterone serum levels (A) and adrenocorticotropic hormone (ACTH) plasma levels (B) $2 \mathrm{~h}$ following lipopolysaccharide (LPS) challenge. Notes: Hormone levels are expressed as natural logarithm ( $\mathrm{ln}$ ) of the concentration ( $\mathrm{ng} / \mathrm{mL}$ and pg/mL, respectively) ( $\mathrm{n}=5$ to $8 / \mathrm{group} / \mathrm{cohort}$ ). Mean serum concentration levels

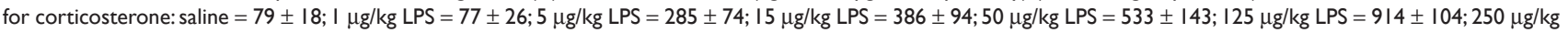
LPS $=658 \pm 145$. Mean plasma concentration levels for ACTH: saline $=316 \pm 169 ; \mathrm{I} \mu \mathrm{g} / \mathrm{kg}$ LPS $=469 \pm 443 ; 5 \mu \mathrm{g} / \mathrm{kg}$ LPS $=647 \pm 553 ; 15 \mu \mathrm{g} / \mathrm{kg}$ LPS $=1092 \pm 330 ; 50 \mu \mathrm{g} / \mathrm{kg}$ LPS $=619 \pm 158 ; 125 \mu \mathrm{g} / \mathrm{kg}$ LPS $=975 \pm 3 ; 250 \mu \mathrm{g} / \mathrm{kg}$ LPS $=665 \pm 157$. Asterisks represent significant differences detected by planned comparisons performed between individual treatment groups and vehicle group. ${ }^{* *} p<0.01$; ${ }^{* * *} p<0.001$.

a specific avoidance of the palatable solution. The present results are in part consistent with previous research which has reported profound decreases in the intake of palatable substances, reduction in the total fluid consumption and no alteration in water intake following high dose of LPS challenge: these effects have been proposed to reflect a lower capacity of LPS-treated rats to experience pleasure and being regarded as anhedonic state. ${ }^{21,26}$ As discussed above, in the present study low doses of LPS $(1-5 \mu \mathrm{g} / \mathrm{kg})$ do affect neither locomotion nor the body weight across a $24 \mathrm{~h}$ period following endotoxin challenge. Thus, the reduced preference for saccharin showed by LPS at low doses may be specific to the effects of LPS on reward rather than being the result of a general behavioral inhibition on fluid intake. The aversion to palatable solution observed at higher doses of LPS $(15 \mu \mathrm{g} / \mathrm{kg}$ and above) may be difficult to explain due to the fact that the anhedonic component is not distinguishable from major side effects including an overall inhibitory effect of LPS on thirst (adipsia), psychomotor deficit as well as physical debilitation (ie, impaired locomotion and weigh loss). 


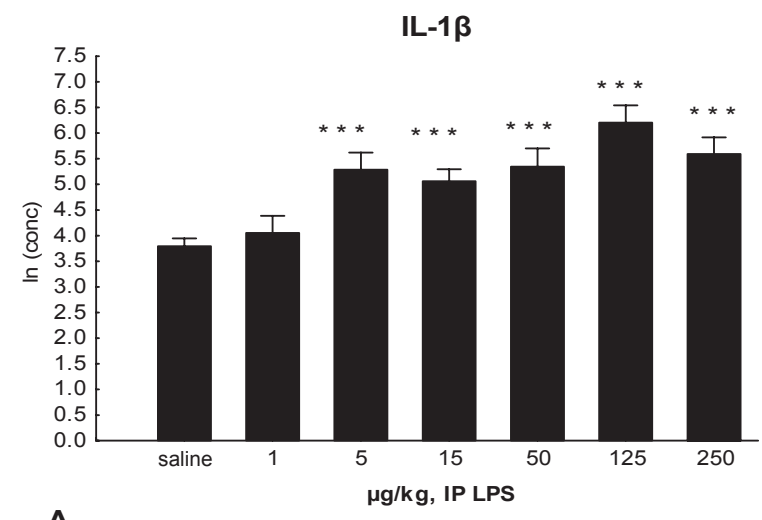

A

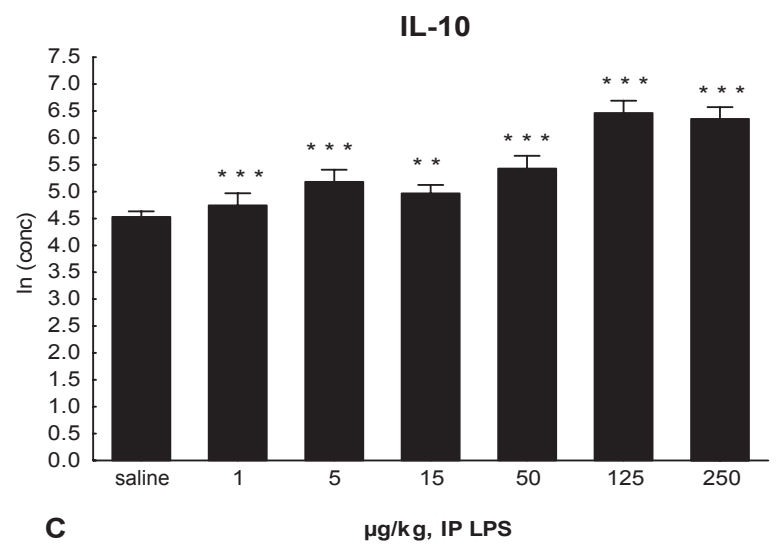

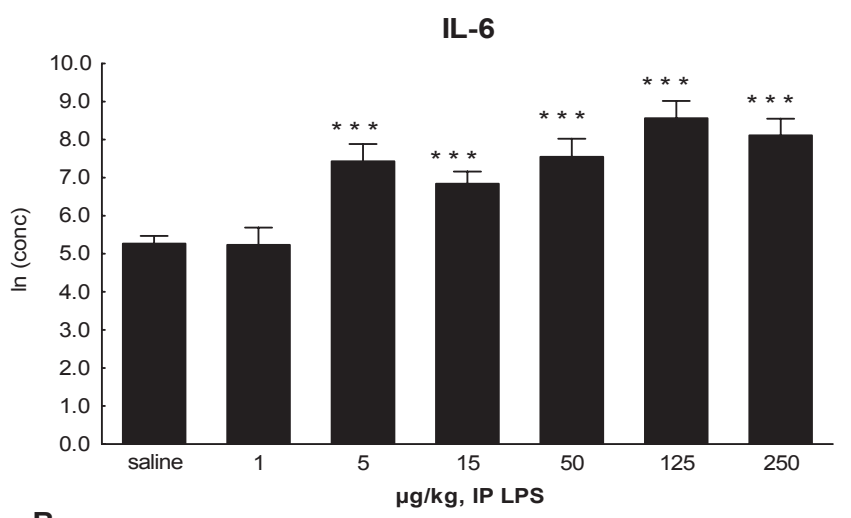

B

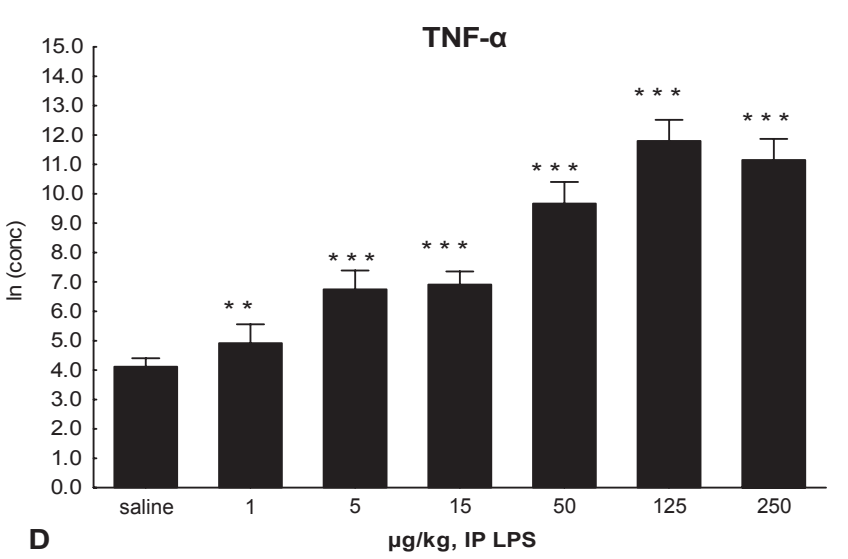

Figure 6 Cytokine levels in rat serum $2 \mathrm{~h}$ following lipopolysaccharide (LPS) treatment. Interleukin I- $\beta$ (ILI- $\beta$ ) (A), IL-6 (B), IL-I0 (C), and tumor necrosis factor alpha $(\mathrm{TNF}-\alpha)(\mathbf{D})$.

Notes: All values are expressed as natural logarithm (ln) of the serum concentration ( $\mathrm{pg} / \mathrm{mL})(\mathrm{n}=5$ to 8 rats/group/cohort). Mean concentration serum level \pm SEM for IL-I $\beta$ : saline $=50 \pm 6 ; 1 \mu \mathrm{g} / \mathrm{kg}$ LPS $=109 \pm 38 ; 5 \mu \mathrm{g} / \mathrm{kg}$ LPS $=277 \pm 42 ; 15 \mu \mathrm{g} / \mathrm{kg}$ LPS $=216 \pm 53 ; 50 \mu \mathrm{g} / \mathrm{kg}$ LPS $=247 \pm 88 ; 125 \mu \mathrm{g} / \mathrm{kg}$ LPS $=449 \pm 32 ; 250 \mu \mathrm{g} / \mathrm{kg}$ LPS $=316 \pm 64$. Mean concentration serum level for IL-6: saline $=240 \pm 39 ; 1 \mu \mathrm{g} / \mathrm{kg} \mathrm{LPS}=304 \pm 184 ; 5 \mu \mathrm{g} / \mathrm{kg} \mathrm{LPS}=1617 \pm 220 ; 15 \mu \mathrm{g} / \mathrm{kg} \mathrm{LPS}=1415 \pm 382 ; 50 \mu \mathrm{g} / \mathrm{kg} \mathrm{LPS}=28 \mathrm{II} \pm 757$;

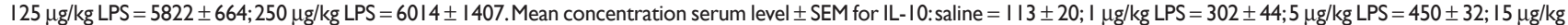
LPS $=245 \pm 52 ; 50 \mu \mathrm{g} / \mathrm{kg}$ LPS $=162 \pm 45 ; \mathrm{I} 25 \mu \mathrm{g} / \mathrm{kg}$ LPS $=434 \pm 42 ; 250 \mu \mathrm{g} / \mathrm{kg}$ LPS $=490 \pm 97$. Mean concentration serum level \pm SEM for TNF- $\alpha:$ saline $=91 \pm 20 ; \mathrm{I} \mu \mathrm{g} / \mathrm{kg}$ LPS $=334 \pm 74 ; 5 \mu \mathrm{g} / \mathrm{kg}$ LPS $=2410 \pm 649 ; 15 \mu \mathrm{g} / \mathrm{kg}$ LPS $=8871 \pm 4466 ; 50 \mu \mathrm{g} / \mathrm{kg}$ LPS $=40412 \pm 26534 ; 125 \mu \mathrm{g} / \mathrm{kg}$ LPS $=88375 \pm 14214 ; 250 \mu \mathrm{g} / \mathrm{kg}$ LPS $=53032 \pm 13436$. Asterisks represent significant differences detected by planned comparisons between individual treatment groups and vehicle group. $*^{*} p<0.01 ; * * * p<0.00 \mathrm{I}$.

LPS challenge also affected the release of peripheral cytokines and HPA axis hormones. Systemic administration of LPS, from 5 to $250 \mu \mathrm{g} / \mathrm{kg}$, increased in a dose-dependent manner the production of peripheral cytokines IL-1ß and IL-6 whereas the IL-10 as well TNF- $\alpha$ were found to increase significantly at all doses of LPS tested. Particularly, in agreement with present findings, a rapid increase in serum TNF- $\alpha$ and a slower elevation in IL- $1 \beta$ and IL- 6 were demonstrated after systemic administration of low doses of LPS, while following administration of high doses of LPS, a TNF- $\alpha$ peak was triggered simultaneously to IL- $1 \beta$ and IL-6 peaks. ${ }^{37}$

A large increase in the serum or plasma concentrations of both corticosterone and ACTH was also detected starting from the LPS dose of 5 and $15 \mu \mathrm{g} / \mathrm{kg}$, respectively. The present results are consistent with previous studies, which have reported increases in HPA axis hormone levels following LPS administration at comparable doses. ${ }^{38,39} \mathrm{HPA}$ axis stimulation following systemic LPS is also produced by the activation of hypothalamic nuclei (ie, paraventricular nucleus) and by the increased expression of CRF as the latter is considered an important mediator for LPS-induced ACTH secretion..$^{40-44}$ These neuroendocrine effects are not due to a direct pharmacological action of LPS, rather to its function as a potent inducer of synthesis and secretion of numerous cytokines such as IL-1ß, IL-6, TNF- $\alpha$, which are the most likely mediators of LPS effects on neuroendocrine secretion. ${ }^{45}$

Overall, in the present study we reproduced, at least in part, the symptoms induced by LPS administration in many clinical and preclinical studies, defined generally as "sickness behavior" ${ }^{26,46}$ However it has to be highlighted that the most positive attribute of the present investigation is that a wide range of doses $(1,5,15,50,125$, and $250 \mu \mathrm{g} / \mathrm{kg}$ IP) has 
been assessed on a coherent and multifaceted number of measures. Also, for the first time LPS has been behaviorally characterized using the LABORAS ${ }^{\circledR}$ system which has several advantages over conventional methodologies as multiple behaviors can be automatically scored in a single experiment and over a much longer duration with continuous monitoring to be undertaken.

Interestingly, these behavioral effects are associated with the stimulation of the immune response and a less pronounced pattern of change in the HPA activity, suggesting that behavioral deficits may not be directly linked to the neuroendocrine activation and reinforcing the hypothesis that cytokines are the key mediators of the sickness behavior. ${ }^{24,47}$ Cytokines may induce changes in the CNS through different mechanisms such as direct diffusion into the brain, ${ }^{48,49}$ peripheral production of pro-inflammatory mediators which in turn may diffuse into the $\mathrm{CNS}^{50}$ and activation of specific receptors expressed on the vagus nerve abdominal terminals, ${ }^{51-53}$ thus generating a feedback signal to the brain, ultimately producing behavioral responses..$^{54,55}$ In support to the latter hypothesis, Bluthe and colleagues ${ }^{56,57}$ demonstrated that sickness behavior including a decrease in social interaction induced by administration of either LPS or IL-1ß, was blocked following vagotomy, suggesting a selective involvement of the vagus nerve in the psychological component of the syndrome induced by LPS. Therefore a similar mechanism may be underlying the effects presently observed (ie, low doses interacting selectively with the vagal function). Furthermore other pro-inflammatory mediator not assessed in the current study, such as IL-2, known to induce sickness behavior, ${ }^{58}$ could also have been involved in the behavioral changes observed.

In addition, indirect pharmacological evidence has started to accumulate which classifies sickness behavior as a depressive-like syndrome, that may be relevant to the clinical condition of depression and if confirmed may open new avenues to help our understanding of this debilitating psychiatric condition. ${ }^{59}$ Furthermore, changes in the circulating cytokine levels of TNF- $\alpha$ as well as IL-6 or IL-1 receptor antagonist, and alterations in emotional states such as increased symptoms of anxiety and depression, but not physical sickness symptoms, have been reported in healthy volunteers following low amounts of endotoxin $(0.8 \mathrm{ng} / \mathrm{kg}$ body weight-intravenous).$^{60}$ Interestingly, the result of this clinical study also demonstrated that endotoxin-induced increases in anxiety and depressed mood are strongly associated with the extent of cytokines secretion rather than HPA axis activation suggesting that these two systems may be differentially involved in coordinating the behavioral response associated with sickness behavior. However it should be considered that a direct translation of our results into the clinical setting has some limitations. For instance if on the one hand the cytokine dynamic following LPS challenge is reported to be very dose-dependent in human, on the other hand the magnitude of the cytokine response to endotoxin seems to be highly individual. In particular, the scientific literature suggests that either genetic polymorphism or age as well as gender may all play a critical role for variations during endotoxemia. ${ }^{61-63}$

In conclusion, the present finding reveals that LPS caused a decrease in the social behavior as well as induced profound changes in the hedonic state even at very low doses. Furthermore the administration of high doses of LPS causes a massive release of both cytokines and stress hormones with severe consequences on general behavior and physiological parameters, suggesting that the use of such high doses should be avoided in behavioral studies.

These findings are worthy of further studies to elucidate potential mechanisms involved in LPS-induced syndrome in the rat. Given the possible similarities between the syndrome induced in rodents and humans, such studies may provide a preclinical model for the investigation of potential therapeutic approaches for inflammatory-mediated mood disorders in humans.

\section{Acknowledgments}

We gratefully acknowledge C Righetti for technical support in collecting animal blood samples; Dr F Marini for expert assistance and Dr D Wille 'for helpful advice on the statistical analysis approach.

\section{References}

1. Maes M. Major depression and activation of the inflammatory response system. Adv Exp Med Biol. 1999;461:25-46.

2. Sluzewska A. Indicators of immune activation in depressed patients. Adv Exp Med Biol. 1999;461:59-73.

3. Maes M. Psychological stress and the inflammatory response system. Clin Sci (Lond). 2001;101:193-194.

4. Zorrilla EP, Luborsky L, McKay JR, et al. The relationship of depression and stressors to immunological assays: a meta-analytic review. Brain Behav Immun. 2001;15:199-226.

5. Miller GE, Rohleder N, Stetler C, Kirschbaum C. Clinical depression and regulation of the inflammatory response during acute stress. Psychosom Med. 2005;67:679-687.

6. Connor TJ, Leonard BE. Depression, stress and immunological activation: the role of cytokines in depressive disorders. Life Sci. 1998;62:583-606.

7. Maes M, Lin AH, Delmeire L, et al. Elevated serum interleukin-6 (IL-6) and IL-6 receptor concentrations in posttraumatic stress disorder following accidental man-made traumatic events. Biol Psychiatry. 1999;45:833-839. 
8. Mikova O, Yakimova R, Bosmans E, Kenis G, Maes M. Increased serum tumor necrosis factor alpha concentrations in major depression and multiple sclerosis. Eur Neuropsychopharmacol. 2001;11:203-208.

9. Thomas AJ, Davis S, Morris C, Jackson E, Harrison R, O'Brien JT. Increase in interleukin-1beta in late-life depression. Am J Psychiatry. 2005;162:175-177.

10. Pollak Y, Yirmiya R. Cytokine-induced changes in mood and behaviour: implications for 'depression due to a general medical condition', immunotherapy and antidepressive treatment. Int J Neuropsychopharmacol. 2002;5:389-399.

11. Hauser P, Khosla J, Aurora H, et al. A prospective study of the incidence and open-label treatment of interferon-induced major depressive disorder in patients with hepatitis C. Mol Psychiatry. 2002;7:942-947.

12. Musselman DL, Lawson DH, Gumnick JF, et al. Paroxetine for the prevention of depression induced by high-dose interferon alfa. $N$ Engl J Med. 2001;344:961-966.

13. Raetz CR, Whitfield C. Lipopolysaccharide endotoxins. Ann Rev Biochem. 2002;71:635-700.

14. Vedder H, Schreiber W, Yassouridis A, Gudewill S, Galanos C, Pollmacher T. Dose-dependence of bacterial lipopolysaccharide (LPS) effects on peak response and time course of the immune-endocrine host response in humans. Inflamm Res. 1999;48:67-74.

15. Martich GD, Boujoukos AJ, Suffredini AF. Response of man to endotoxin. Immunobiology. 1993;187:403-416.

16. Ottaway CA, Fong IW, Da Silva B, Singer W, Karras L. Integrative aspects of a human model of endotoxemia. Can J Physiol Pharmacol. 1998;76:473-478

17. Schreiber W, Pollmacher T, Fassbender K, et al. Endotoxin- and corticotropin-releasing hormone-induced release of ACTH and cortisol. A comparative study in men. Neuroendocrinology. 1993;58:123-128.

18. Reichenberg A, Yirmiya R, Schuld A, et al. Cytokine-associated emotional and cognitive disturbance in humans. Arch Gen Psychiatry. 2001;58:445-452.

19. Borowski T, Kokkinidis L, Merali Z, Anisman H. Lipopolysaccharide, central in vivo biogenic amine variations, and anhedonia. Neuroreport. 1998;9:3797-3802.

20. Fishkin RJ, Winslow JT. Endotoxin-induced reduction of social investigation by mice: interaction with amphetamine and antiinflammatory drugs. Psychopharmacology (Berl). 1997;132:335-341.

21. Shen Y, Connor TJ, Nolan Y, Kelly JP, Leonard BE. Differential effect of chronic antidepressant treatments on lipopolysaccharideinduced depressive-like behavioral symptoms in the rat. Life Sci. 1999;65:1773-1786.

22. Dantzer R. Bluthe RM, Laye S, Bret-Dibat JL, Parnet P, Kelley KW. Cyotokines and sickness behaviour. J Ann NY Acad Sci. 1998;840:586-590.

23. Quinn LP, Stean TO, Trail B, et al. LABORAS: Initial pharmacological validation of a system allowing continuous monitoring of laboratory rodent behaviour. J Neurosci Methods. 2003;130:83-92.

24. Bluthe RM, Dantzer R, Kelley KW. Effects of interleukin-1 receptor antagonist on the behavioral effects of lipopolysaccharide in rat. Brain Res. 1992;573:318-320.

25. Yirmiya R, Rosen H, Donchin O, Ovadia H. Behavioral effects of lipopolysaccharide in rats: involvement of endogenous opioids. Brain Res. 1994;648:80-86.

26. Yirmiya R. Endotoxin produces a depressive-like episode in rats. Brain Res. 1996;711:163-174.

27. Hrupka BJ, Langhans W. A role for serotonin in lipopolysaccharide-induced anorexia in rats. Pharmacol Biochem Behav. 2001;68:355-362.

28. Lugarini F, Hrupka BJ, Schwartz GJ, Plata-Salaman CR, Langhans W. A role for cyclooxygenase-2 in lipopolysaccharide-induced anorexia in rats. Am J Physiol Regul Integr Comp Physiol. 2002;283: R862-R868.

29. Aubert A, Dantzer R. The taste of sickness: lipopolysaccharide-induced finickiness in rats. Physiol Behav. 2005;84:437-444.
30. Plata-Salaman CR, Borkoski JP. Centrally administered bacterial lipopolysaccharide depresses feeding in rats. Pharmacol Biochem Behav. 1993;46:787-791.

31. Bluthe RM, Castanon N, Pousset F, et al. Central injection of IL-10 antagonizes the behavioral effects of lipopolysaccharide in rats. Psychoneuroendocrinology. 1999;24:301-311.

32. Yirmiya R, Pollak Y, Barak O, et al. Effects of antidepressant drugs on the behavioral and physiological responses to lipopolysaccharide (LPS) in rodents. Neuropsychopharmacology. 2001;24:531-544.

33. Dogan MD, Ataoglu H, Akarsu ES. Effects of different serotypes of Escherichia coli lipopolysaccharides on body temperature in rats. Life Sci. 2000;67:2319-2329.

34. Dogan MD, Ataoglu H, Akarsu ES. Characterization of the hypothermic component of LPS-induced dual thermoregulatory response in rats. Pharmacol Biochem Behav. 2002;72:143-150.

35. Szekely M, Szelenyi Z. Endotoxin fever in the rat. Acta Physiol Acad Sc Hung. 1979;53:265-277.

36. Romanovsky AA, Almeida MC, Aronoff DM, et al. Fever and hypothermia in systemic inflammation: recent discoveries and revisions. Front Biosci. 2005;10:2193-2216.

37. Zuckerman SH, Shellhaas J, Butler LD. Differential regulation of lipopolysaccharide-induced interleukin 1 and tumor necrosis factor synthesis: effects of endogenous and exogenous glucocorticoids and the role of the pituitary-adrenal axis. Eur J Immunol. 1989;19:301-305.

38. Givalois L, Dornand J, Mekaouche M, et al. Temporal cascade of plasma level surges in ACTH, corticosterone, and cytokines in endotoxinchallenged rats. Am J Physiol. 1994;267:R164-R170.

39. Takao T, Nanamiya W, Takemura T, et al. Endotoxin induced increases in rat plasma pituitary-adrenocortical hormones are better reflected by alterations in tumor necrosis factor alpha than interleukin-1beta. Life Sci. 1997;61:263-268.

40. Kakucksa L, Qi Y, Clark BD, Lechan RM. Endotoxin-induced corticotrophin-releasing hormone gene expression in the hypothalamic paraventricular nucleus is mediated centrally by interleukin-1. Endocrinology. 1993;133:815-821.

41. Rivest S, Laflamme N, Nappi RE. Immune challenge and immobilization stress induce transcription of the gene encoding the CRF receptor in selective nuclei of the rat hypothalamus. J Neurosci. 1995;15:2680-2695.

42. Sagar SM, Price KJ, Kasting NW, Sharp FR. Anatomic patterns of FOS immunostaining in the rat brain following systemic endotoxin administration. Brain Res Bull. 1995;36:381-392.

43. Wan WL, Wetmore CM, Sorenson CM, Greenberg AH, Nance DM. Neural and biochemical mediators of endotoxin and stress-induced c-fos expression in the rat brain. Brain Res Bull. 1994;34:7-14.

44. Tilders FJH, Schmidt ED, De Goelj DCE. Phenotypic plasticity of CRF neurons during stress. Ann NY Acad Sci. 1993;697:39-52.

45. Anisman H, Merali Z, Poulter MO, Hayley S. Cytokines as a precipitant of depressive illness: animal and human studies. Curr Pharm Des. 2005;11:963-972.

46. Kent S, Bluthe RM, Kelley KW, Dantzer R. Sickness behavior as a new target for drug development. Trends Pharmacol Sci. 1992;13:24-28.

47. Watkins LR, Maier SF. Immune regulation of central nervous system functions: from sickness responses to pathological pain. J Intern Med. 2005;257:139-155.

48. Licinio J, Wong ML. Pathways and mechanisms for cytokine signaling of the central nervous system. J Clin Invest. 1997;100:2941-2947.

49. Buller KM. Role of circumventricular organs in pro-inflammatory cytokine-induced activation of the hypothalamic-pituitary-adrenal axis. Clin Exp Pharmacol Physiol. 2001;28:581-589.

50. Cao C, Matsumura K, Watanabe Y. Induction of cyclooxygenase-2 in the brain by cytokines. Ann. N Y Acad Sci. 1997;813:307-309.

51. Ek M, Kurosawa M, Lundeberg T, Ericsson A. Activation of vagal afferents after intravenous injection of interleukin-1beta: role of endogenous prostaglandins. J Neurosci. 1998;18:9471-9479.

52. Goehler LE, Gaykema RP, Hammack SE, Maier SF, Watkins LR. Interleukin-1 induces c-Fos immunoreactivity in primary afferent neurons of the vagus nerve. Brain Res. 1998;804:306-310. 
53. Goehler LE, Gaykema RP, Nguyen KT, et al. Interleukin-1beta in immune cells of the abdominal vagus nerve: a link between the immune and nervous systems? J Neurosci. 1999;19:2799-2806.

54. Dantzer R, Konsman JP, Bluthe RM, Kelley KW. Neural and humoral pathways of communication from the immune system to the brain: parallel or convergent? Auton Neurosci. 2000;85:60-65.

55. Konsman JP, Luheshi GN, Bluthe RM, Dantzer R. The vagus nerve mediates behavioral depression, but not fever, in response to peripheral immune signals; a functional anatomical analysis. Eur J Neurosci. 2000;12:4434-4446.

56. Bluthe RM, Walter V, Parnet P, et al. Lipopolysaccharide induces sickness behavior in rats by a vagal mediated mechanism. C R Acad Sci (III). 1994;317:499-503.

57. Bluthe RM, Michaud B, Kelley KW, Dantzer R. Vagotomy blocks behavioral effects of interleukin-1 injected via the intraperitoneal route but not via other systemic routes. Neuroreport. 1996;7:2823-2827.
58. Lacosta S, Merali Z, Anisman H. Influence of acute and repeated interleukin-2 administration on spatial learning, locomotor activity, exploratory behaviors, and anxiety. Behav Neurosci. 1999;113:1030-1041.

59. Yirmiya R, Pollak Y, Morag M, et al. Illness, cytokines, and depression. Ann N Y Acad Sci. 2000;917:478-487.

60. Reichenberg A, Yirmiya R, Schuld A, et al. Cytokine-associated emotional and cognitive disturbances in humans. Arch Gen Psychiatry. 2001;58:445-452.

61. Calvano JE, Bowers DJ, Coyle SM, et al. Response to systemic endotoxemia among humans bearing polymorphisms of the Toll-like receptor 4 (hTLR4). Clin Immun. 2006;121:186-190.

62. Krabbe KS, Bruunsgaard H, Hansen CM, et al. Ageing is associated with a prolonged fever response in human endotoxemia. Clin Diagn Lab Immun. 2001;8:333-338.

63. Van Eijk LT, Dorresteijn MJ, Smits P, et al. Gender differences in the innate immune response and vascular reactivity following the administration of endotoxin to human volunteers. Crit Care Med. 2007;35:1464-1469. 
